\title{
ALGICIDAL EFFECT OF EXTRACTS FROM A GREEN MACROLAGAE (CHARA VULGARIS) ON THE GROWTH OF THE POTENTIALLY TOXIC CYANOBACTERIUM (MICROCYSTIS AERUGINOSA)
}

\author{
DOUMA, M. ${ }^{1 *}$ - TAZART, Z. ${ }^{2}$ - TEBAA, L. ${ }^{2}$ - El BouAidi, W. ${ }^{2}$ - HAKKOUM, Z. ${ }^{2}-$ MinAOUI, F. ${ }^{2}-$ \\ LAZRAK, K. ${ }^{2}-$ MANAUT, N. ${ }^{3}-$ MOUHRI, K. ${ }^{2}-$ LOUDIKI, M. $^{2}$ \\ ${ }^{I}$ Natural Resources Engineering and Environmental Impacts Team, \\ Multidisciplinary Research and Innovation Laboratory, Polydisciplinary Faculty of Khouribga \\ (FPK), Sultan Moulay Slimane University, Beni-Mellal 23000, Morocco
}

${ }^{2}$ Water, Biodiversity and Climate Change Laboratory; Phycology, Biotechnology and Environmental Toxicology Research Unit; Faculty of Sciences Semlalia, Cadi Ayyad University, Av. Prince My Abdellah P.O. Box 2390, Marrakech 40000, Morocco

${ }^{3}$ Cadi Ayyad University, Faculty of Sciences Semlalia, Laboratory of Microbial Biotechnology, Agrosciences and Environment, 40000 Marrakesh, Morocco

*Corresponding author

e-mail: douma_mountasser@yahoo.fr; phone: +212-(061)-967-057

(Received $1^{\text {st }}$ May 2021; accepted 30 ${ }^{\text {th }}$ Aug 2021)

\begin{abstract}
The extracts of Chara vulgaris (a green macroalgae) were tested to explore its algicidal potential on Microcystis aeruginosa growth. Firstly, the anticyanobacterial effect of both macroalgae aqueous (MAA) and macroalgae etyl acetate (MEA) extracts against M. aeruginosa was assessed using both the paper disc diffusion and microdilution methods. Minimum inhibitory concentrations (MIC) and minimum algicidal concentrations (MAC) were evaluated. Secondly, the growth of $M$. aeruginosa in response to the MEA extracts was investigated in an experimental bioassay. To reveal the potential allelochemicals, total phenols (TPs), total flavonoids (TFs), tannins (TTs) were analyzed in both MAA and MEA extracts. The identification of the phenolic compounds in MEA extracts was performed by high-performance liquid chromatography (HPLC). The results from the bioassay demonstrated that MEA extracts inhibit the growth of $M$. aeruginosa in a concentration dependent way. The highest inhibition rate (IR) exceeds $83 \%$ on day (d) 4 of experimentation, and achieved (97.98\%) on 7-d. HPLC analysis revealed seven phenolic compounds known as effective allelochemicals. Overall, the obtained results demonstrate that MEA extracts might be proposed as a potential allelochemicals, and it can be considered as an ecofriendly alternative algaecide to control Microcystis blooms in the eutrophic water bodies.
\end{abstract}

Keywords: Chara vulgaris, natural algaecides, allelochemicals, M. aeruginosa, inhibitory effect

\section{Introduction}

Harmful algal blooms (HABs) constitute a major human health risk and an environmental problem worldwide. Cyanobacterial blooms have occurred extensively in superficial eutrophic freshwater bodies used for recreational purposes and drinking water sources (De Figueiredo et al., 2004). Microcystis spp. are the most common bloom-forming cyanobacteria in eutrophic freshwaters (Douma et al., 2016). Microcystis blooms occurrences are frequently toxic and are able to produce hepatotoxins (Microcystins) which are responsible for the contamination of drinking water, and for the intoxication of many vegetal and animal organisms (Douma et al., 2017). 
In order to control the proliferation of toxic cyanobacteria, several solutions have been used. The classical approaches recommended to reduce algal proliferation were often chemical and physical methods (eg; algaecide addition, centrifugation, filtration, flocculation); however, these measures induce secondary pollution ( $\mathrm{Li}$ et al., 2016). Biological control approaches using aquatic plants have emerged as economic and ecofriendly alternatives. Various aquatic macrophytes have been used to inhibit several kinds of cyanobacteria and green algae such as Myriophyllum spicatum ,Ceratophyllum demersum, Najas marina, Najas minor (Zhang et al., 2014), Elodea spp. Eichhornia crassipes, Nymphaea tetragona, Typha orientalis, Nelumbo nucifera, and Irris wilsonii (Chen et al., 2012), Sagittaria trifolia (Li et al., 2016). However, among the submerged aquatic macrophytes, freshwater and brackish water macrolagae are little studied (Zhang et al., 2009).

Phytochemical characterization of macrophytes indicated that the revealed constituents are allelechemical products. The most important of these bioactive constituents are flavonoids, tannins, alkaloids, fatty acids and several phenolic compounds ( $\mathrm{Li}$ and $\mathrm{Hu}, 2005$; Chen et al., 2012; Zhang et al., 2014; Canton et al., 2019). More specific allelochemicals on the inhibition of Microcystis spp. were previously identified and purified from aquatic plants. The most effective allelochemicals were Ethyl 2-Methyl Acetoacetate (EMA), N-phenyl-2-naphthylamine and Pyrogallol acid (Li and Hu, 2005; Pei et al., 2018).

Hydrophyte flora is very common in Mediterranean area such as Morocco, which is known by high biodiversity. Several invasive and/or native aquatic plants proliferate intensively in several wetlands. Among these, freshwater and brakish water macroalgae that belongs to Characeae family. Chara vulgaris is a freshwater species, generally developing in very shallow waters, in temporary ponds, rivers, thermal springs or seepages of inundated meadows, with high resistance to eutrophication (Zouaïdia et al., 2015; Muller et al., 2017). The Characeae family had known an important interest in many pharmacological uses, with antimicrobial activities (Cai et al., 2013). Also, some species belonging to this family have been recognized in algicidal activities against various microalgae including Microsytis spp (Kurashov et al., 2021; Zhu et al., 2021).

Our hypothesis is that allelochemicals from Chara vulgaris var. vulgaris have antialgal potential and could inhibit the growth of $M$. aeruginosa. The aim of this study was to assess the algicidal effects of Chara vulgaris on $M$. aeruginosa; with regard to growth inhibition, photosynthetic comportment, and characterization of the potential allelochemicals.

\section{Materials and methods}

\section{Biological materials}

M. aeruginosa was isolated from eutrophic Lalla Takerkoust reservoir, Morocco, $\left(31^{\circ} 21^{\prime} 36^{\prime \prime} \mathrm{N} ; 8^{\circ} 7^{\prime} 48^{\prime \prime} \mathrm{W}\right)$ in October 2015 , and was grown in laboratory cultures at $26{ }^{\circ} \mathrm{C} \pm 2{ }^{\circ} \mathrm{C}$ under light intensity of $65 \mu \mathrm{E} / \mathrm{m}^{2} / \mathrm{S}$, with a light/dark cycle of $15 \mathrm{~h} / 9 \mathrm{~h}$.

Biological material of the macroalgae was collected in April 2016 from an urban pond in Marrakesh city, and identified as Chara vulgaris var. vulgaris. The whole plant was rinsed several times with distilled water to remove debris, and conserved for farther use. 


\section{Preparation of macroalgae Aqueous (MAA) and ethyl acetate (MEA) extracts}

$20 \mathrm{~g}$ of fresh biomass was cut into small pieces in $300 \mathrm{~mL}$ of distilled water under agitation for $48 \mathrm{~h}$ at room temperature. The solution was filtered through glass fiber papers (Whatman GF/C, $0.22 \mu \mathrm{m}$ ). The filtrate was collected as an aqueous extract for the biological test and for further fractionations. The aqueous extract was fractionated according to Wang et al. (2010) and Tazart et al. (2020a). Briefly, the filtrate was adjusted to $\mathrm{pH} 12$ with $2 \mathrm{M} \mathrm{NaOH}$. The alkaline extract was centrifuged at $6000 \mathrm{rpm}$ for 10 min. The supernatant was transferred to a separating funnel and washed three times with $200 \mathrm{~mL}$ hexane. The aqueous fraction was acidified to $\mathrm{pH} 5$ with $2 \mathrm{M} \mathrm{HCl}$ and then extracted three times with $100 \mathrm{~mL}$ ethyl acetate. The ethyl acetate extracts were first dried with anhydrous sodium sulfate and then evaporated to dryness by rotary evaporator at $39{ }^{\circ} \mathrm{C}$. The ethyl acetate extracts were stored at $4{ }^{\circ} \mathrm{C}$ until used for biological assay.

\section{Total phenols (TPs), total flavonoids (TFs), tannins (TTs) concentrations determination in LA extracts}

TPs concentration was determined with the Folin-Ciocalteu method (Singleton et al., 1965). Briefly, $0.5 \mathrm{ml}$ of the extract was added to $0.5 \mathrm{ml}$ of Folin-Ciocalteu reagent (Sigma-Aldrich) in water, and then $0.5 \mathrm{ml}$ sodium carbonate solution $(20 \% \mathrm{w} / \mathrm{v})$ was added. The mixture was left for $1 \mathrm{~h}$ at room temperature and absorbance was measured at $760 \mathrm{~nm}$. TFs content concentration was determined by the method described by Kim (2003). Briefly, $500 \mu l$ of aqueous extract was mixed with $500 \mu l$ distilled water. Then $150 \mu \mathrm{l}$ sodium nitrite solution $(5 \%)$ was added, followed by $150 \mu 1$ aluminum chloride solution $(10 \%)$ after $5 \mathrm{~min}$. Test tubes were incubated for $11 \mathrm{~min}$ at ambient temperature, and then $500 \mu \mathrm{l}$ sodium hydroxide $(1 \mathrm{M})$ was added. The mixture was vortexed and absorbance was determined at $510 \mathrm{~nm}$. TTs content was determined with Folin-Denis test described by Salunkhe and Chavan (1989). Briefly, $1 \mathrm{ml}$ of the aqueous extract was added to $75 \mathrm{ml}$ distilled water, and then $5 \mathrm{ml}$ Folin Denis reactif (SigmaAldrich) solution and $10 \mathrm{ml}$ sodium carbonate solution was added. The mixture was vortexed and absorbance was determined after $30 \mathrm{mn}$ at $760 \mathrm{~nm}$.

\section{Minimal inhibitory concentration (MIC) and minimal algicidal concentration (MAC) determinations}

The MIC preventing visible algal growth was measured by the broth dilution method developed by the Clinical and Laboratory Standards Institute (CLSI) using 96-well microplates (Hammer et al., 1996; Joshi et al., 2016). The MAA and MEA concentrations were ranged from 0.78 to $100 \mathrm{mg} / \mathrm{L}$. The MEA were prepared by dissolution in $0.1 \%$ dimetyl sulfoxyde (DMSO). Subsequently in each well of 96 well plates, $100 \mu 1$ of plant extracts concentrations were added to $100 \mu 1$ of test microalgae of $3.10^{6}$ Cells $/ \mathrm{mL}$ (exponential growth phase). Inoculated microplate were incubated after careful mixing under controlled conditions in a culture room at $26 \pm 2{ }^{\circ} \mathrm{C}$, illuminated in $15 \mathrm{~h} / 9 \mathrm{~h}$ light-dark cycle with fluorescent tubes $\left(65 \mu \mathrm{E} / \mathrm{m}^{2} / \mathrm{S}\right)$. The MIC of each extract was defined as the lowest concentration which inhibited either microalgal growth. The MAC was determined by subculture on microplate under the same controlled conditions of clear wells, which did not show any visible growth after incubation during the test. Copper sulphate was used as algicidal positive controls with the concentrations ranged from 0.001 to $0.1 \mathrm{mg} / \mathrm{L}$. 


\section{Disc diffusion assay}

$M$. aeruginosa was used for susceptibility-screening tests using the disc diffusion method (Kil et al., 2009). Sterilized filter paper discs of $9 \mathrm{~mm}$ were saturated with $20 \mu \mathrm{l}$ of MAA or MEA extracts prepared in the Z8 medium with $0.1 \%$ of DMSO. Copper sulphate with a concentration of $10 \mu \mathrm{g}$ were used as positive controls and $(0.1 \%)$ of DMSO was used as negative control. Anticyanobacterial activity was measured by the formation of inhibition zones (in $\mathrm{mm}$ ) around the discs where the extracts tested were applied.

\section{Algicidal activity bioassay}

The bioassay was conducted according to Tazart et al. (2019, 2020b), with some modifications. 6 groups of Erlenmeyer flasks $(500 \mathrm{ml})$ containing Z8 medium (Kotai, $1972)$ to a final volume $(300 \mathrm{ml})$ were used. Each flask was inoculated by a volume of $M$. aeruginosa, in exponential growth phase, to make an initial density $\left(11-12 \times 10^{5} \mathrm{cell} / \mathrm{ml}\right)$. The macrophyte ethyl acetate (MEA) extracts were dissolved in dimethyl sulfoxide (DMSO) $0.1 \%(\mathrm{v} / \mathrm{v}$ ) and added to $300 \mathrm{ml}$ of $M$. aeruginosa cultures to obtain final concentrations (0 (control), 25, 50, 75, 100; mg/l). An untreated equal volume of cyanobacterial culture with $0.1 \%$ of DMSO was used as negative control. Flasks were incubated under controlled conditions in a culture room at $26 \pm 2{ }^{\circ} \mathrm{C}$, illuminated in $15 \mathrm{~h} / 9 \mathrm{~h}$ light-dark cycle with fluorescent tubes $(65 \mu \mathrm{E} / \mathrm{m} 2 / \mathrm{S})$ within 7 -d. All the experiments were conducted in triplicate. $M$. aeruginosa growth under different treatments was quantified daily using Malassez hemocytometer. Inhibitory rate (IR) of M. aeruginosa growth was determined according to the following Eq.1:

$$
\operatorname{IR}(\%)=\frac{N 0-N}{N 0} \times 100
$$

where No and $\mathrm{N}$ are the cell density (cells/ml)in the treatment and control cultures, respectively.

\section{Pigments determination}

Chlorophyll-a and Carotenoids pigments were calculated according to Lichtenthaler and Wellburn (1983). They extracted with Ethanol $95 \%$ at $4{ }^{\circ} \mathrm{C}$ for $48 \mathrm{~h}$, and then determined using a UV-Spectrophotometer (Carré 50 Scan) at 470, 649, $665 \mathrm{~nm}$. The following formulas were used to calculate the concentrations as mentioned in the Eq.2 and Eq.3:

$$
\begin{gathered}
{[\text { Chlorophylle a }]=(13.95 * \text { D0665) }-(6.88 * \text { D0649 })} \\
{[\text { Caroténoïdes }]=\frac{[(1000 * \text { D0470 })-(2.05 \text { chla })]}{229}}
\end{gathered}
$$

where Chla and Carot. represent the concentration of chlorophyll-a and Carotenoids $(\mu \mathrm{g} / \mathrm{ml})$ respectively; OD470, OD649 and OD665 are wavelengths absorbance $(\mathrm{nm})$. 


\section{Identification and quantification of phenolic compounds by HPLC}

In order to identify the phenolic compounds in MEA extracts, the samples were filtered first through Whatman filter paper $\mathrm{N}^{\circ} 42$ and then through $0.22 \mathrm{~mm}$ membrane filters (Millipore). Phenolic compounds were separated using HPLC with a $250 \mathrm{~mm} \times 4.6 \mathrm{~mm}, 5.0 \mu \mathrm{m}$ reversed-phase (RP-18) column (Agilent Technologies) and a $10 \mathrm{~mm} \times 4.6 \mathrm{~mm}$ RP-18 pre-column (Agilent Technologies). The two columns were placed into a column furnace at $25{ }^{\circ} \mathrm{C}$. The HPLC system consists of an automated injector (Shimadu SCL-10A series pumping system, SIL-10AD) coupled to a SPD 10A UV-visible detector (set to start at $200 \mathrm{~nm}$ and end at $700 \mathrm{~nm}$ ). Data collection and analysis were performed using the Shimadu LC Solution chromatography data station software. Two solvents were used in a constant flow rate of $0.1 \mathrm{ml} / \mathrm{min}$, with an injection volume of $10 \mu \mathrm{l}$. Solvent A consisted of acetonitrile (5\%) and water $(95 \%)$, solvent $\mathrm{B}$ is a phosphate buffer solution in water $(\mathrm{pH}=2.6)$. All solvents employed were HPLC-grade. The following proportions of solvent B were used for the elution program. Standards were run on the machine first, followed by plant extracts and then samples. Phenolic compounds were identified by comparing their retention times to those of the standards.

\section{Statistical analysis}

Data with three replicates were statistically analyzed by two-way analysis of variance (ANOVA) with Tukey's test to assess differences between exposure concentrations and those untreated (control) at different concentrations and over the time at $\mathrm{p}=0.05$. Correlation coefficients were calculated between cellular density and PTs, FTs, TTs concentrations in the end of experimentation.

\section{Results}

\section{Anticyanobacterial activity assessment}

The anti-cyanobacterial activity of the extracts was evaluated qualitatively using the disk diffusion methods and quantitatively by the broth microdilution methods in 96 wells. The results were presented in Figure 1 and Table 1. The results indicate that the MIC and MAC had equal concentrations values for each extract. For the macroalgae extracts, the most important activity against $M$. aeruginosa was observed under MEA extract with $(31 \pm 1 \mathrm{~mm}$; MIC $=$ MAC $=25 \mathrm{mg} / \mathrm{l})$, followed by the MAA extract with $(16.67 \pm 0.58 \mathrm{~mm} ; \mathrm{MIC}=\mathrm{MAC}=50 \mathrm{mg} / \mathrm{L})$. The Copper sulphate as a positive control showed the greatest effectiveness with the MIC and MAC $=3.12 \mathrm{mg} / \mathrm{l}$. Thus, the tested MEA extracts appear to have a more pronounced anti-cyanobacterial activity (Table 1).

\section{Effects on M. aeruginosa growth}

Based on their relative stronger inhibitory effects, the MEA extracts were chosen to conduct a bioassay. As shown in Figure 2, it can be seen that MEA extracts may inhibit the growth of $M$. aeruginosa and exhibited a concentration dependent trend. In control group, the cell densities remained between $11.86 \times 10^{5}$ and $133.63 \times 10^{5}$ cell $/ \mathrm{mL}$ over the test period. Conversely, the cell densities of $M$. aeruginosa at tested concentrations $(25,50,75$ and $100 \mathrm{mg} / \mathrm{l})$ were reduced during the 7 -d test period. The detailed data on the IRs through the test period was listed in Table 2. Indeed, Microcystis growths appeared significantly reduced $(\mathrm{p}<0.05)$ by the tested concentrations; with an overall 


$$
-4786-
$$

inhibition rates (IRs) exceeding globally $50 \%$ after 4 -d at the $50 \mathrm{mg} / \mathrm{l}$ concentration (Fig. 2, Table 2). Under the highest concentration $(100 \mathrm{mg} / \mathrm{l})$ of MEA extracts, the inhibition rate (IR) exceeds $83 \%$ on 4 -d of experimentation; and it was achieved $(97.98 \%)$ on 7 -d.
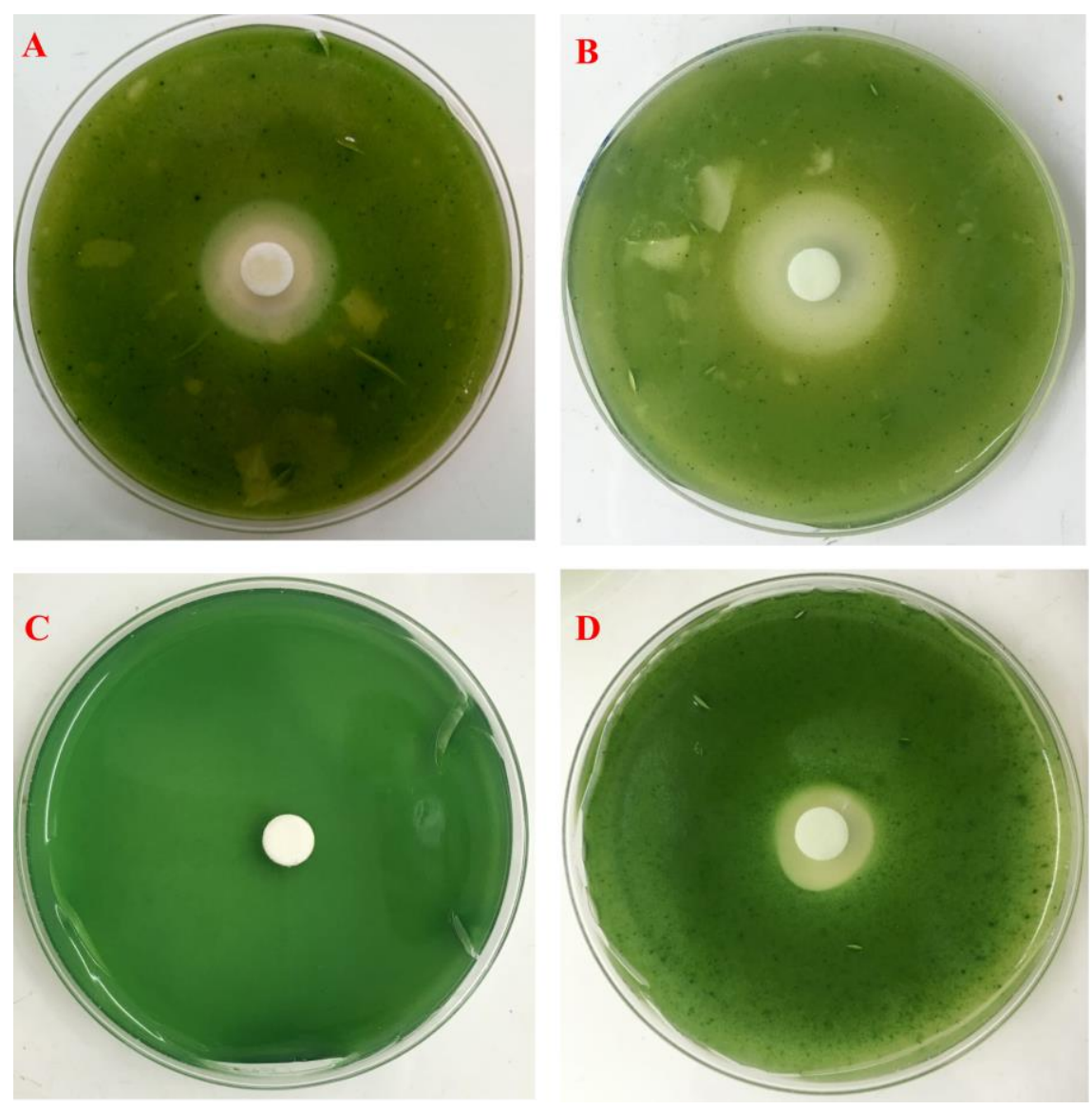

Figure 1. Antialgal activity: aqueous (A) and (B) Ethyl acetate extracts; DMSO (C) and Copper sulphate $(D)$

Table 1. Results of Anticyanobacterial activity assessment using the disk diffusion and microdilution methods

\begin{tabular}{c|c|c|c|c|c|c}
\hline & \multicolumn{2}{|c|}{ Test on solid media } & \multicolumn{4}{c}{ Microdilution methods } \\
\hline & $\begin{array}{c}\text { Inhibition zone diameter on } \\
\text { Microcystis aeruginosa }(\mathrm{mm})\end{array}$ & $\begin{array}{c}\text { Minimal inhibitory } \\
\text { concentration (MIC) (mg/l) }\end{array}$ & $\begin{array}{c}\text { Minimal bactericidal } \\
\text { concentration (MAC) (mg/l) }\end{array}$ \\
\hline $\begin{array}{c}\text { Chara } \\
\text { Extracts }\end{array}$ & Aqueous & Ethyl acetat & Aqueous & Ethyl acetat & Aqueous & Ethyl acetat \\
\hline Means & $16.67 \pm 0,58$ & $\mathbf{3 1 . 0 0} \pm 1$ & 50 & $\mathbf{2 5}$ & 50 & $\mathbf{2 5}$ \\
\hline $\begin{array}{c}\text { Copper } \\
\text { sulphate }\end{array}$ & \multicolumn{2}{|c|}{$14.67 \pm 1.15$} & \multicolumn{5}{c}{$3.12 \pm 1.15$} \\
\hline DMSO & \multicolumn{7}{c|}{0.00} \\
\hline
\end{tabular}

*: Similar values indicate here the standard deviation $(n=3)$ 


$$
-4787 \text { - }
$$

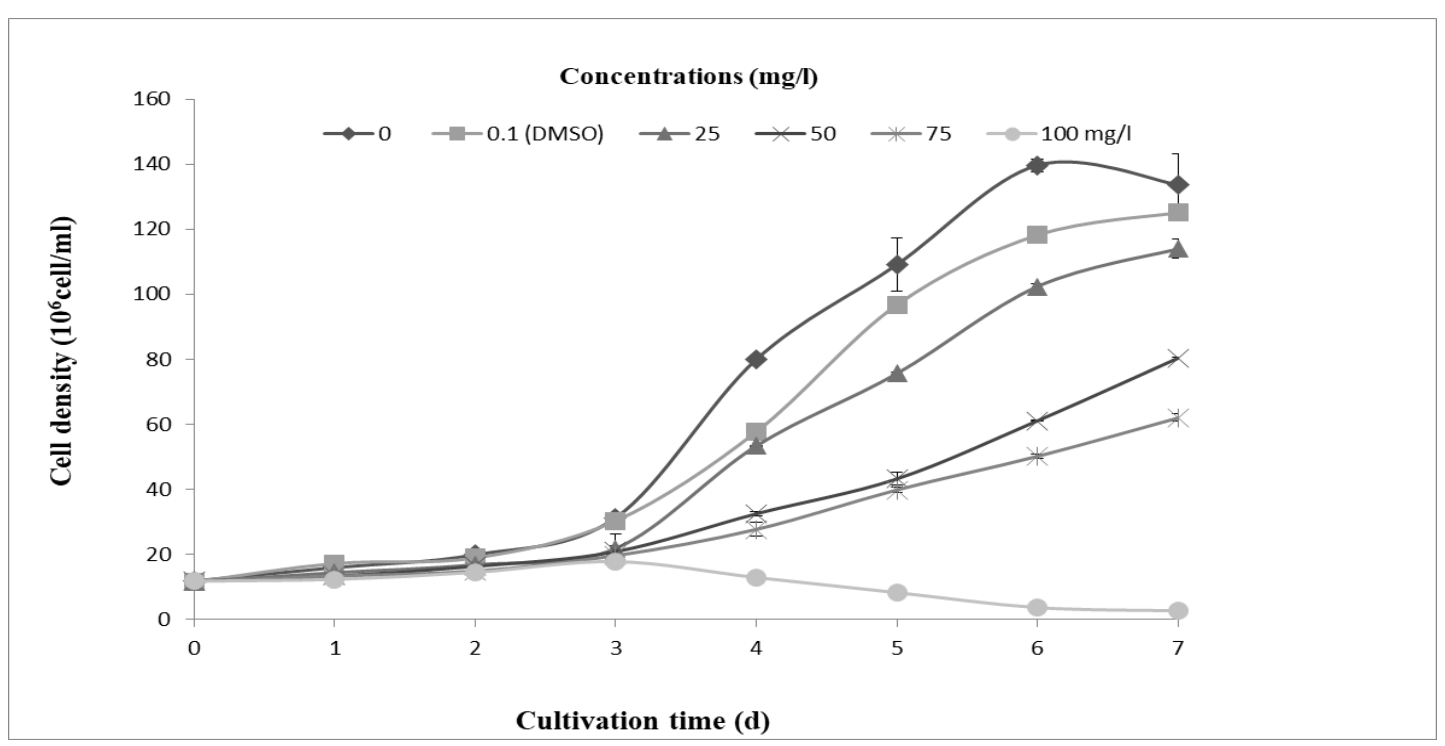

Figure 2. Effects of the different concentrations of MEA extracts on M. aeruginosa growth. Errors bars represent the standard deviation $(n=3) . * 0.05$ indicate significant differences compared to the untreated culture (ANOVA tow-way)

Table 2. The inhibitory effects expressed as inhibitory rate (\%) of MEA extracts on M. aeruginosa growth

\begin{tabular}{c|c|c|c|c|c|c|c|c}
\hline $\begin{array}{c}\text { Treatements } \\
(\mathbf{m g} / \mathbf{L})\end{array}$ & $\mathbf{0}$ & $\mathbf{1}$ & $\mathbf{2}$ & $\mathbf{3}$ & $\mathbf{4}$ & $\mathbf{5}$ & $\mathbf{6}$ & $\mathbf{7}$ \\
\hline $\mathbf{0 . 1}$ & $2.39 \pm 0$ & $-7.73 \pm 1$ & $4.86 \pm 2$ & $3.09 \pm 3$ & $27.85 \pm 4$ & $11.34 \pm 5$ & $15.39 \pm 6$ & $6.41 \pm 7$ \\
& $1.97 \pm$ & $9.82 \pm$ & $15.42 \pm$ & $30.25 \pm$ & $33.27 \pm$ & $30.69 \pm$ & $26.71 \pm$ & $14.74 \pm$ \\
$\mathbf{2 5}$ & 2.54 & 15.63 & 2.32 & 4.88 & 0.07 & 0.05 & 0.29 & 1.88 \\
& $0.98 \pm$ & $16.5 \pm$ & $17.93 \pm$ & $33.34 \pm$ & $\mathbf{5 9 . 3 6} \pm$ & $\mathbf{6 0 . 3 8} \pm$ & $\mathbf{5 6 . 2 6} \pm$ & $39.86 \pm$ \\
$\mathbf{5 0}$ & 2.54 & 7.78 & 3.03 & 18.98 & $\mathbf{0 . 2 2}$ & $\mathbf{0 . 3 6}$ & $\mathbf{0 . 7 9}$ & 2.94 \\
& $1.12 \pm$ & $16.5 \pm$ & $25.13 \pm$ & $37.28 \pm$ & $\mathbf{6 5 . 3 7} \pm$ & $\mathbf{6 3 . 4 9} \pm$ & $\mathbf{6 4 . 0 8} \pm$ & $\mathbf{5 3 . 6 3} \pm$ \\
$\mathbf{7 5}$ & 1.99 & 11.04 & 4.03 & 7.95 & $\mathbf{1 . 2 3}$ & $\mathbf{2 . 2 8}$ & $\mathbf{0 . 2 9}$ & $\mathbf{0 . 2 6}$ \\
& $0.7 \pm$ & $22.77 \pm$ & $27.14 \pm$ & $43.14 \pm$ & $\mathbf{8 3 . 8 8} \pm$ & $\mathbf{9 2 . 4 3} \pm$ & $\mathbf{9 7 . 3 8} \pm$ & $\mathbf{9 7 . 9 8} \pm$ \\
$\mathbf{1 0 0}$ & 2.74 & 11.04 & 16.15 & 4.52 & $\mathbf{3 . 2 9}$ & $\mathbf{1 . 0 9}$ & $\mathbf{0 . 6 2}$ & $\mathbf{1 . 1}$ \\
\hline
\end{tabular}

*: Similar values indicate here the standard deviation $(n=3)$

\section{Effects on photosynthetic pigments}

In order to assess the physiological modification, two photosynthetic pigments were measured (Chl-a and carotenoids). Under control treatment, the Chl-a and carotenoids concentrations increase as a function of tested concentrations (Fig. 3A,B). By contrast, in treatments they decrease negatively with the augmentation of extract concentrations. The content pigment concentrations are appearing to be strongly inhibited at the all treatments since 5-d. The significant differences between the concentration in treatment and controls groups were remarquably observed for Chl-a $(\mathrm{p}<0.05)$ and carotenoids after 5-d and 7-d, respectively (Fig. 3A,B). 


\section{Concentrations $(\mathrm{mg} / \mathrm{l})$}
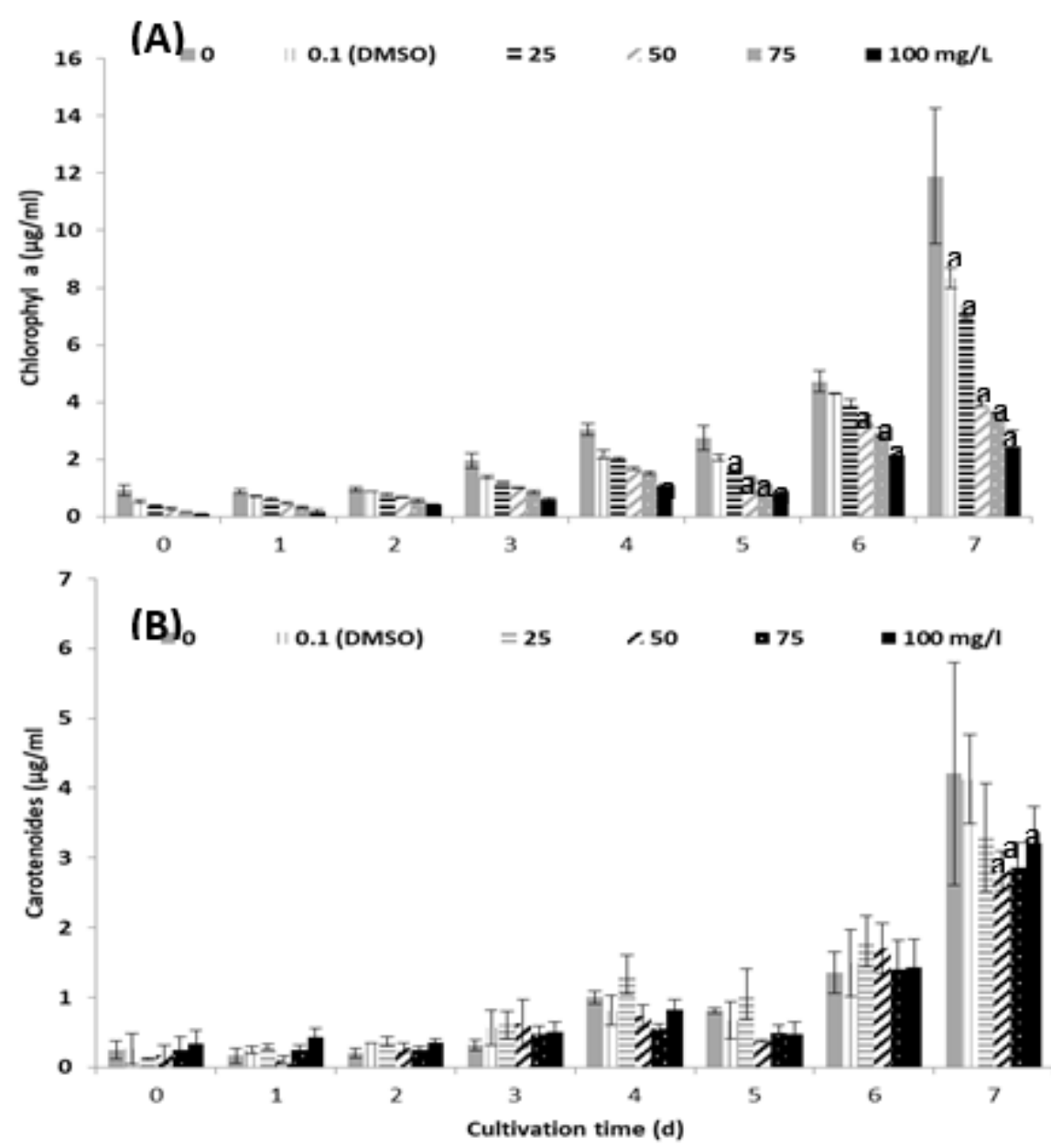

Figure 3. Effects of Chara sp. ethyl acetate extract on Chl-a (A) and carotenoides (B) in M. aeruginosa cultures, respectively. Each value is the mean $\pm S D$ of three replicates, a indicate significant differences compared to the untreated culture (ANOVA tow-way) at $p<0.05$

\section{Phytochemical characterization}

The results of the phytochemical characterization are shown in Table 3. MEA extract exhibited important values on TPs, TFs, and TTs. As well, a high significant correlation $(0.97)$ have been well obtained between the IRs of the three high concentrations of TPs $(50,75,100 \mathrm{mg} / \mathrm{l})$ in the end of the experiment.

Table 3. Total phenolic (TPs), Total flavonoids (TFs), Total tannins (TTs) amounts in MEA extracts; and correlations between all amounts and IRs of the three high after 7 days of exposure

\begin{tabular}{c|c|c|c}
\hline & TPs $^{\mathbf{1}}$ & TFs $^{\mathbf{2}}$ & TTs $^{\mathbf{3}}$ \\
\hline Concentrations & 124.35 & 101.02 & 0,08 \\
Coefficient of correlation & $\mathbf{0 . 9 7}$ & 0.75 & 0.93 \\
\hline
\end{tabular}

${ }^{(1)}$ : $\mu \mathrm{g}$ Gallic acide quivalent $/ \mathrm{mL}$ extract, $\left({ }^{2}\right): \mu \mathrm{g}$ catechin equivalent $/ \mathrm{mL}$ extract, $\left({ }^{3}\right): \mu \mathrm{g}$ tannic acid equivalents $/ \mathrm{mL}$ extract 
HPLC technique was used to identify and quantify the major phenolic compounds in MEA extracts. From the HPLC chromatogram (Fig. 4 and Table 4), 7 different chemicals were identified from the three MEA extracts. Characterization of major phenolic components from MEA extract was dominated by p-coumaric acid $(36.58 \%)$ of the total identified compounds, followed by caffeic acid (25.78\%), Catechic acid $(23.37 \%)$, tanic acid $(21.03 \%)$, sorbic acid $(6.06 \%)$ and rutic acid $(4.47 \%)$, and furulic acid $(1.36 \%)$.

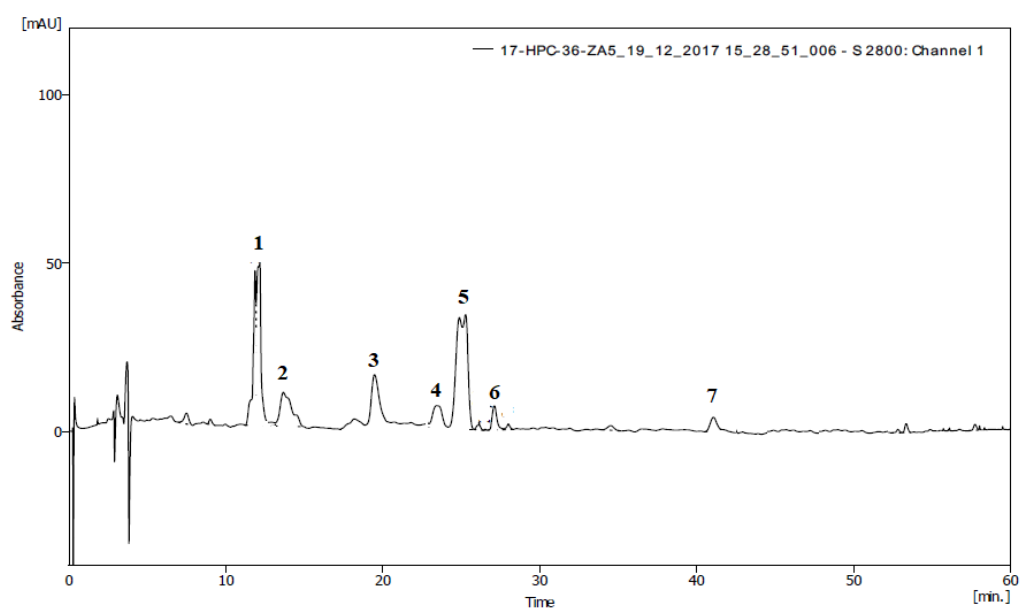

Figure 4. HPLC chromatogram recorded at $280 \mathrm{~nm}$ for the main phenolic compounds identified in the Chara sp. ethyl-acetate extracts: 1) catechic acid, 2) tanic acid, 3) cafféic acid, 4) ferrulic acid, 5) p-coumaric acid, 6) sorbic acid and 7) rutic Acid

Table 4. Concentrations of the main phenolic compounds identified in the Chara sp. ethyl acetate extracts expressed in $\mathrm{mg} E G A / g$ DM

\begin{tabular}{c|c|c|c|c|c}
\hline Compound N & $\begin{array}{c}\text { Retention } \\
\text { Time }[\mathbf{m i n}]\end{array}$ & Area [mAU.s] & Compound & $\begin{array}{c}\text { Concentrations } \\
(\mathbf{m g} \text { EGA /g } \\
\text { DM) }\end{array}$ & $\begin{array}{c}\text { \% of } \\
\text { Compounds }\end{array}$ \\
\hline $\mathbf{1}$ & 11.9 & 581.353 & Catechic acid & 23.37 & $20 \%$ \\
$\mathbf{2}$ & 13.7 & 522.861 & Tanic acid & 21.03 & $18 \%$ \\
$\mathbf{3}$ & 19.5 & 641.564 & Cafféic acid & 25.78 & $22 \%$ \\
$\mathbf{4}$ & 23.4 & 31.106 & Ferrulic acid & 1.36 & $1 \%$ \\
$\mathbf{5}$ & 24.9 & 911.536 & p-coumaric acid & 36.58 & $31 \%$ \\
$\mathbf{6}$ & 27.1 & 148.454 & Sorbic acid & 6.06 & $5 \%$ \\
$\mathbf{7}$ & 41.1 & 108.862 & Rutic Acid & 4.47 & $4 \%$ \\
\hline
\end{tabular}

\section{Discussion}

In search of an ecofriendly algaecide to control cyanoHABs, several bioactive compounds from macrophytes were screened and characterized which may be important sources of allelochemicals. In the present study, the antialgal activities of the MAA and MEA extracts were assessed qualitatively and quantitatively in both solid and liquid medium. Based on their relative stronger inhibitory effect, the MEA extracts were used to conduct an experimental bioassay. 
The obtained results confirmed that the MEA extracts act negatively on the $M$. aeruginosa growth in a dose dependent manner. For the MEA extract, the highest inhibition rate (IR) exceeds $83 \%$ on day 4 of experimentation; and it was achieved $(97.98 \%)$ on $7-d$. These results remain globally similar to those observed in other previous works that studied macrophyte aqueous and etyl acetat extracts on Microcystis spp. Tazart et al. (2019, 2020a,b) showed that the growth of M. aeruginosa was effectively inhibited by macrophyte aqueous and ethyl acetate extracts, with strongest inhibition rates (IR values between 95 and 100\%) for Ranunculus aquatilis, Nasturtium officinale and Potamogeton natans.

Similar results were observed with the use of other macrophytes aqueous extracts such as Spartina alterniflora with $\mathrm{IR}=99.4 \%$ (Yuan et al., 2020), both Cyperus alternifolius and Canna generalis with more than $\mathrm{IR}=99.6 \%$ (Zhou et al., 2019). These strong inhibitions demonstrated the relative high algicidal potential of macrophyte extracts compared to those of certain terrestrial plants: Ailanthus altissima (66.3-91.8\%) on $5 \mathrm{~d}$ (Meng et al., 2015), S. trifolia (70\%) after $6 \mathrm{~d}$ (Li et al., 2016), Thalia dealbata (92.7\%) on 7-d (Zhang et al., 2011), N. tetragona, T. orientalis, N. nucifera and I. wilsonii (75-82\%) during 19 d (Chen et al., 2012), Achillea ageratum, Origanum compactum (88-95) after $8 \mathrm{~d}$ (Tebaa et al., 2017; 2018).

Although many aquatic and terrestrial plants, and marine algae have been tested to control Microcystis harmful blooms; freshwater macroalgae are very little studied. To our knowledge, the freshwater Chara genus is the most recognized in bioassays that have tested the algaecide effect on Microcystis spp (Berger and Schagerl, 2004).

In our experimental study, the growth inhibition is well confirmed by the decrease of the two photosynthetic pigments (Chl-a and carotenoids) in treatments groups. The growth inhibition accompanied by photosynthetic pigments reduction and morphological changes of $M$. aeruginosa, were mainly indicators of physiological alterations under a stress environment in several works (Meng et al., 2015; Li et al., 2016). Also, some studies showed specially the negative effect of the extracts on Chl-a content (Ni et al., 2012; Meng et al., 2015). Their decrease shows the disturbance of the photosynthesis affecting the growth and reproduction of $M$. aeruginosa (Li et al., 2016). Zhu et al. (2010) demonstrated that polyphenols, pyrogallic acid and gallic acid produced by $M$. spicatum decreased the photosynthetic activity of the cyanobacterium species by inhibiting the activity of PSII.

This inhibitory effect might be related to potential allelochemicals released by Chara vulgaris. From the obtained results, it seems that TPs participate more in the inhibitory activity (Tables 3 and 4). These results agreed with previous works showing the effect of PTs, in the $M$. aeruginosa inhibition (Chen et al., 2012). In fact, the phytochemical investigation of extracts allowed the identification of several other compounds. They are mainly flavonoids, glycosides, terpenoids, saponins and several phenolic acids (Li and $\mathrm{Hu}, 2005$; Chen et al., 2012; Li et al., 2016). However, plant-derived polyphenolics were the most common allelochemicals in HABs control (Zhu et al., 2021).

In the only study devoted to the characterization of allelochemicals of Chara vulgaris, Zhang et al. (2009) reported three phenolic coumpounds (The (Z, Z)-9,12octadecadienoic, tetradecanoic and hexadecanoic acides) as the potent allelochemicals for Chara vulgaris L. against the toxic M. aeruginosa. In our study, the characterization of major phenolic components from MEA extracts of the Moroccan Chara vulgaris var. vulgaris, showed the dominance of p-coumaric acid (36.58\%), caffeic acid $(25.78 \%)$, Catechic acid (23.37\%), tanic acid (21.03\%) over the other identified compounds: 
sorbic acid (6.06\%) and rutic acid (4.47\%), and furulic acid (1.36\%) (Table 4). Among the 3 major phenolic compounds, p-coumaric acid is recognized as an effective allelochemical on $M$. aeruginosa (Wang et al., 2010). However, it is rarely identified from macrophytes (Agnihotri et al., 2008). In the other hand, caffeic acid and Catechic acid, are often repeated as effective allelochemicals (Gao and Xie, 2011; Gao et al., 2015; Zhu et al., 2021).

It is well known that the allelochemical compounds inhibited the growth of the cell through the perturbation of the cellular structure as and the physiological statute (Gigova and Ivanova, 2014). Phenolic acids exhibit cell-permeability features due to their amphiphilic and lipophilic nature (Lan et al., 2020). Wang et al. (2016) found that p-coumaric acid and ferulic acid disrupted the cell membrane integrity of M. aeruginosa. Furthermore, under stress conditions, the Reactive Oxygen Species (ROS) act on cell membranes through the degradation of unsaturated phospholipids (Meng et al., 2015), allowing to the increased of their permeability. Thus, the perturbations of antioxidant defense system leading to the inhibition of photosynthesis and oxygen evolution through interactions with components of photosystem II (PS II) (Einhellig, 1995), and finally to induce the cell death (Zhang et al., 2011).

\section{Conclusion}

This study demonstrates the inhibitory effect of the MEA extracts of Chara macroalgae on the $M$. aeruginosa growth. This effect is dose-dependent. TPs characterized might be the main responsible allelochemicals. MEA extracts might be recommend as a potential allechemicals, and it can be considered as an ecofriendly alternative algaecide to control Microcystis blooms. Other future approaches will be necessary to assess its potential effects in mesocosms and in field studies, and against non-target organisms.

Acknowledgements. This work was supported by the Laboratory of Water, Biodiversity and Climate Change Laboratory; Phycology, Biotechnology and Environmental Toxicology Research Unit. The useful comments of anonymous reviewers are also acknowledged.

Conflict of interests. The authors declare no conflict of interests.

\section{REFERENCES}

[1] Agnihotri, V. K., Elsohly, H. N., Khan, S. I., Smillie, T. J., Khan, I. A., Walker, L. A. (2008): Antioxidant constituents of Nymphaea caerulea flowers. - Phytochemistry 69: 2061-2066.

[2] Berger, J., Schagerl, M. (2004): Allelopathic activity of Characeae. - Biologia, Bratislava 59(1): 9-15.

[3] Cai, J., Xie, S., Feng, J. (2013): Antimicrobial activities of Nitellopsis obtusa (Desvaux) Groves and Chara vulgaris L. - Journal of Applied Botany and Food Quality 86: 24-32.

[4] Canton, M. C., Holguin, F. O., Boeing, W. J. (2019): Alkaloid gramine to control algal invaders: Algae inhibition and gramine persistence. - Bioresour Technol Reports 7: 100304.

[5] Chen, J. Z., Zhang, H. Y., Han, Z. P., Ye, J. Y., Liu, Z. (2012): The influence of aquatic macrophytes on Microcystis aeruginosa growth. - Ecological Engineering 42: 130-133. doi: 10.1016/j.ecoleng.2012.02.021. 
[6] De Figueiredo, D. R., Azeiteiro, U. M., Esteves, S. M., Goncalves, F. J. M., Pereira, M. J. (2004): Microcystin-producing blooms - a serious global public health issue. Ecotoxicology and Environmental Safety 59: 151-163.

[7] Douma, M., Manaut, N., Oudra, B., Loudiki, M. (2016): First report of cyanobacterial diversity and microcystins in a Microcystis strain from a Mediterranean coastal lagoon (Sidi Boughaba, Morocco). - African Journal of Aquatic Science 41(4): 445-452.

[8] Douma, M., Ouahid, Y., Loudiki, M., del Campo, F. F., Oudra, B. (2017): The first detection of potentially toxic Microcystis strains in two Middle Atlas Mountains natural lakes (Morocco). - Environmental Monitoring and Assessment 189: 1-9. doi: 10.1007/s10661-016-5753-x.

[9] Einhellig, F. A. (1995): Mechanism of action of allelochemicals in allelopathy. - In: Inderjit Einhellig, F. A., Dakshini, K. M. M. (eds.) Allelopathy: Organisms, Processes, and Applications. American Chemical Society, Washington DC.

[10] Gao, Y., Liu, B., Dong, X., Zhou, Q., Hu, C., Ge, F., Zhang, L., Wu, Z. (2011): Phenolic Compounds Exuded from Two Submerged Freshwater Macrophytes and Their Allelopathic Effects on Microcystis aeruginosa. - Polish Journal of Environmental Studies 20(5): 1153-1159.

[11] Gao, Y., Liu, B., Ge, F., He, Y., Lu, Z., Zhou, Q., Zhang, Y., Wu, Z. (2015): Joint effects ofallelochemical nonanoic acid, N-phenyl-1-naphtylamine and caffeic acid on the growth of Microcystis aeruginosa. - Allelopathy Journal 35(2): 249-257.

[12] Gigova, L., Ivanova, N. (2014): Reponses of Symploca sp. (Cyanobacteria) to Nitrogen depletion during culturing. - Comptes rendus de l'Academie bulgare des Sciences 67(1): 43-48.

[13] Hammer, K. A., Carson, C. F., Riley, T. V. (1996): Susceptibility of transient and commensal skin flora to the essential oil of Melaleuca alternifolia (tea tree oil). American Journal of Infection Control 24: 186-189. doi: 10.1016/S0196-6553(96)900115.

[14] Joshi, A., Prasad, S. K., Joshi, V. K., Hemalatha, S. (2016): Phytochemical standardization, antioxidant, and antibacterial evaluations of Leea macrophylla: A wild edible plant. - Journal of Food and Drug Analysis 24: 324-331. doi: 10.1016/J.JFDA.2015.10.010.

[15] Kil, H., Seong, E., Ghimire, B., Chung, I., Kwon, S., Goh, E., Heo, K., Kim, M., Lim, J., Lee, D., Yu, C. (2009): Antioxidant and antimicrobial activities of crude sorghum extract. - Food Chemistry 115: 1234-1239.

[16] Kim, U-K. (2003): Positional Cloning of the Human Quantitative Trait Locus Underlying Taste Sensitivity to Phenylthiocarbamide. - Science 299: 1221-1225. doi: 10.1126/science.1080190.

[17] Kotai, J. (1972): Instructions for preparation of modified nutrient solution Z8 for algae. Oslo: Norwegian Institute for Water Research Publication B-11/69, Blindem.

[18] Kurashov, E., Krylova, J., Protopopova, E. (2021): The Use of Allelochemicals of Aquatic Macrophytes to Suppress the Development of Cyanobacterial "Blooms". - In: Plankton Communities. IntechOpen edition, doi: 10.5772/intechopen.95609.

[19] Lan, Y., Chen, Q., Gou, T., Sun, K., Zhang, J., Sun, D., Duan, S. (2020): Algicidal Activity of Cyperus rotundus Aqueous Extracts Reflected by Photosynthetic Efficiency and Cell Integrity of Harmful Algae Phaeocystis globosa. - Water 12: 3256. https://doi.org/10.3390/w12113256.

[20] Li, F. M., Hu, H. Y. (2005): Isolation and characterization of a novel antialgal allelochemical from Phragmites communis. - Applied and Environmental Microbiology 71: 6545-6553. doi: 10.1128/AEM.71.11.6545-6553.2005.

[21] Li, J., Liu, Y., Zhang, P., Zeng, G., Cai, X., Liu, S., Yin, Y., Hu, X., Hu, X., Tan, X. (2016): Growth inhibition and oxidative damage of Microcystis aeruginosa induced by crude extract of Sagittaria trifolia tubers. - Journal of environmental sciences 43: 40-47. 
[22] Lichtenthaler, H., Wellburn, A. (1983): Determinations of total carotenoids and chlorophylls b of leaf extracts in different solvents. - Biochem Soc Trans 11: 591-592. doi: $10.1042 / \mathrm{bst0110591.}$

[23] Meng, P., Pei, H., Hu, W., Liu, Z., Li, X., Xu, H. (2015): Allelopathic effects of Ailanthus altissima extracts on Microcystis aeruginosa growth, physiological changes and microcystins release. - Chemosphere 141: 219-226. doi: 10.1016/j.chemosphere.2015.07.057.

[24] Muller, S. D., Rhazi, L., Soulie-Märsche, I., Benslama, M., Bottollier-Curtet, M., DaoudBouattour, A., De Belair, G., Ghrabi-Gammar, Z., Grillas, P., Paradis, L., ZouaïdiaAbdelkassa, H. (2017): Diversity and distribution of Characeae in the Maghreb (Algeria, Morocco, Tunisia). - Cryptogamie Algologie 38(3): 201-251.

[25] Ni, L., Acharya, K., Hao, X., Li, S. (2012): Isolation and identification of an anti-algal compound from Artemisia annua and mechanisms of inhibitory effect on algae. Chemosphere 88: 1051-1057. doi: 10.1016/j.chemosphere.2012.05.009.

[26] Pei, Y., Liu, L., Hilt, S., Xu, R., Wang, B., Li, C., Chang, X. (2018): Root exudated algicide of Eichhornia crassipes enhances allelopathic effects of cyanobacteria Microcystis aeruginosa on green algae. - Hydrobiologia 823: 67-77.

[27] Salunkhe, D. K., Chavan, J. K. (1989): Dietary tannins: consequences and remedies. Boca Raton, Fla. CRC Press.

[28] Singleton, V. L., Rossi, J. A. (1965): Colorimetry of Total Phenolics with Phosphomolybdic-Phosphotungstic Acid Reagents. - American Journal of Enology and Viticulture 16: 144-158. doi: 10.12691/ijebb-2-1-5.

[29] Tazart, Z., Douma, M., Tebaa, L., Loudiki, M. (2019): Use of macrophytes allelopathy in the biocontrol of harmful microcystis aeruginosa blooms. - Water Supply 19: 245-253. doi: 10.2166/ws.2018.072.

[30] Tazart, Z., Caldeira, A. T., Douma, M., Salvador, C., Loudiki, M. (2020a): Inhibitory effect and mechanism of three macrophytes extract on Microcystis aeruginosa growth and physiology. - Water and Environment Journal 35(2): 580-592. doi: 10.1111/wej.12653.

[31] Tazart, Z., Douma, M., Caldeira, A. T., Tebaa, L., Mouhri, K., Loudiki, M. (2020b): Highlighting of the antialgal activity of organic extracts of Moroccan macrophytes: potential use in cyanobacteria blooms control. - Environmental Science and Pollution Research 27: 19630-19637. doi: 10.1007/s11356-020-08440-w.

[32] Tebaa, L., Douma, M., Tazart, Z., Manaut, N., Mouhri, K., Loudiki, M. (2017): Algicidal effects of Achillea ageratum L. and Origanum compactum benth. plant extracts on growth of Microcystis aeruginosa. - Applied Ecology and Environmental Research 15: 719-728. doi: 10.15666/aeer/1504_719728.

[33] Tebaa, L., Douma, M., Tazart, Z., Manaut, N., Mouhri, K., Loudiki, M. (2018): Assessment of the potentially algicidal effects of Thymus satureioides Coss. and Artemisia herba alba L. against Microcystis aeruginosa. - Applied Ecology and Environmental Research 16: 903-912. doi: 10.15666/aeer/1601_903912.

[34] Wang, H., Cheng, S., Zhang, S., He, F., Liang, W., Zhang, L., Hu, C., Ge, F., Wu, Z. (2010): Chemical Composition in Aqueous Extracts of Potamogeton malaianus and Potamogeton maackianus and their Allelopathic Effects on Microcystis aeruginosa. Polish Journal of Environmental Studies 19: 213-218.

[35] Wang, R., Hua, M., Yu, Y., Zhang, M., Xian, Q., Yin, D. (2016): Evaluating the effects of allelochemical ferulic acid on Microcystis aeruginosa by pulse-amplitude-modulated (PAM) fluorometry and flow cytometry. - Chemosphere 147: 264-71.

[36] Yuan, R., Li, Y., Li, J., Ji, S., Wang, S., Kong, F. (2019): The allelopathic effects of aqueous extracts from Spartina alterniflora on controlling the Microcystis aeruginosa blooms. - The Science of the total environment 712: 136332.

[37] Zhang, T. T., He, M., Wu, A. P., Nie, L. W. (2009): Allelopathic effects of submerged macrophyte Charo vulgaris on toxic Microcystis aeruginosa. - Allelopathy Journal 23(2): 391-401. 
[38] Zhang, T., Wang, L., He, Z., Zhang, D. (2011): Growth inhibition and biochemical changes of cyanobacteria induced by emergent macrophyte Thalia dealbata roots. Biochemical Systematics and Ecology 39: 88-94.

[39] Zhang, T., Lu, L., Yang, X., Zhang, S., Xia, W., Li, C. (2014): Allelopathic control of freshwater phytoplankton by the submerged macrophyte Najas minor All. - Acta Ecologica Sinica 34: 351-355.

[40] Zhou, L., Chen, G., Cui, N., Pan, Q., Song, X., Zou, G. (2018): Allelopathic Effects on Microcystis aeruginosa and Allelochemical Identification in the Cuture Solutions of Typical Artificial Floating-Bed Plants. - Bulletin of Environmental Contamination and Toxicology 102: 115-121.

[41] Zhu, J., Liu, B., Wang, J., Gao, Y., Wu, Z. (2010): Study on the mechanism of allelopathic influence on cyanobacteria and chlorophytes by submerged macrophyte (Myriophyllum spicatum) and its secretion. - Aquatic toxicology 98(2): 196-203.

[42] Zhu, X., Dao, G., Tao, Y., Zhan, X., Hu, H. (2020): A review on control of harmful algal blooms by plant-derived allelochemicals. - Journal of hazardous materials 401: 123403.

[43] Zouaïdia, H., Bélair, G., Benslama, M., Soulié-Märsch, I., Muller, S. (2015): Intérêt des Characeae comme bioindicateurs de la qualité des eaux: le cas des zones humides de Numidie (Nord-Est algérien). - Revue d'écologie (Terre et vie) 70: 121-134. 